\title{
A Study of Reflectance of Sandblasted Tile with Different Colors
}

\author{
Bin-Feng Yan, Soen-Han Lee, Yu-Hsin Lin \\ Department of Architecture, National Cheng Kung University \\ No.1, University Road, Tainan City 70101, Taiwan (R.O.C.)
}

\begin{abstract}
This study discussed the reflectance of outdoor compressed concrete paving units. The research samples were basic square ground tiles, including sandblasted tiles with secondary treatment of surface, iridescent crystal sandblasted tiles mixed with waste glass, and rustic tiles. The ASTM E1918A method lately developed by the U.S. Lawrence Livermore National Laboratory (LLNL) was used for measurement. The measurement samples were square ground tiles in length and width of 20CM. The weather on the day was sunny, and the sunshine amount was greater than $800 \mathrm{wa} / \mathrm{m}^{2}$. The measurement site was the top of the $7 \mathrm{th}$ story of research building of Kuang-Fu Campus, National Cheng Kung University, Tainan City. The measurement environment avoided plants, buildings and persons shielding the samples, to avoid the measurement process being disturbed. This study suggests that in order to reduce the urban heat island effect, the white flat tiles without special treatment can be selected as the material for urban outdoor pavement design. Thus, the carbon emission from special treatment can be reduced, and a good reflectance effectiveness can be obtained.
\end{abstract}

Keywords- tainan City; sandblasted tile; iridescent crystal sandblasted; rustic tile; reflectance.

\section{INTRODUCTION}

This phenomenon, the urban heat island, has been recognized since the turn of this century and has been well documented [1-3]. Many measures against environmental problems are developed in buildings, such as restricted use of indoor air conditioning, using high performance thermal insulating building materials, increasing building and peripheral greening and, hoping to reduce and mitigate the deterioration of living environment [4-8]. The thermal characteristics of paved surfaces interacting with solar radiation are among a number of causal factors affecting urban heat island, which also include the population and population density of the urban area, building materials, spacing and height of buildings, waste heat generated by building equipment, as well as vegetative cover, geographic location [9-14].

With urban development, people's range of action extends from indoor space to outdoor space, such as recreation, exercise, performance, diet and leisure, evolving as people's main living space. However, the outdoor environment deteriorates gradually, the considerations and problems in outdoor environment become one of the key points in current environmental design and planning. This study provides material adoption and suggestion for the future planning and design, hoping to describe and analyze the influence by measuring the reflectance of compressed concrete paving units, so as to provide appropriate ground tile materials for different outdoor environmental conditions.

\section{MATERIALS AND METHODS}

\section{A. Research Tools}

An albedometer and a sunshine recorder are used to measure the sample surface reflected radiant quantity. The unit is $\mathrm{W} / \mathrm{m}^{2}$. The measurement follows ASTM E1918A. The albedometer is placed above the measurement samples, measuring white canvas, black canvas and test sample respectively, repeated 5 times to finish measurement. The sample's reflectance is calculated from the obtained data and ASTM E1918A theory. A universal recorder is used to record the sample's reflectance data. The total measurement time is 3 to 4 hours of sample reflectance history, and the instrument records once every $5 \mathrm{sec}$. Finally, the experimental data are integrated into diachronic chart and form for description. 


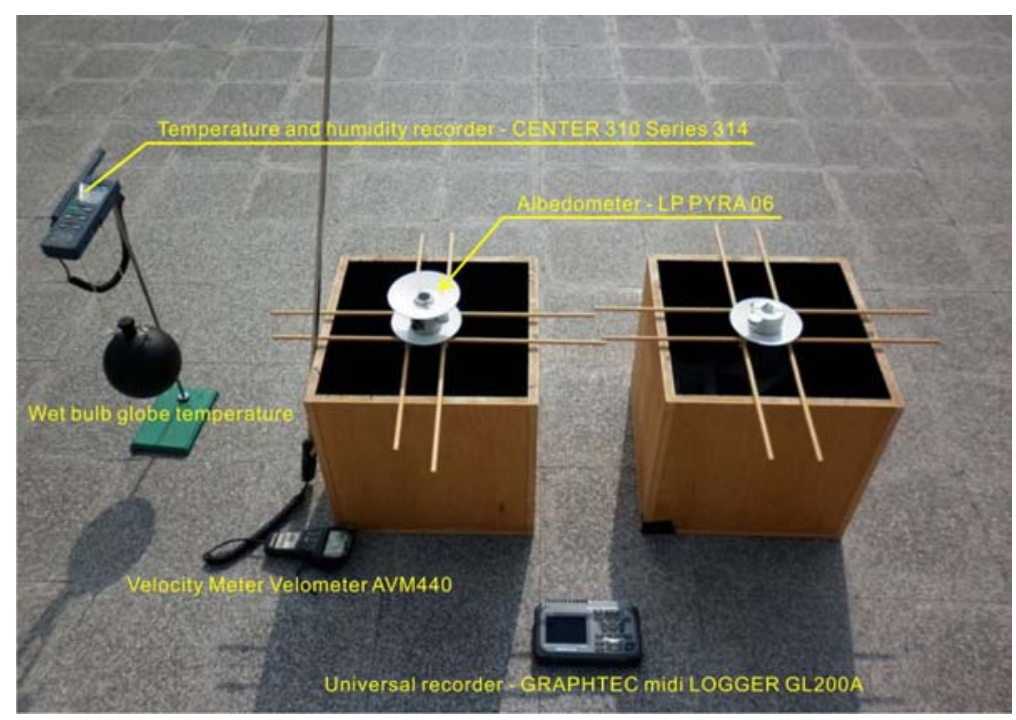

Figure 1. Overall onsite measurement experiment.

The Center 310 humidity meter series comprise good quality RH meters with temperature reading, auto off \& with RS232 output. Model 310 is the base unit with optional PC software - logs when connected to a PC. Model 313 and 314 are data logging units to 16,000 readings \& includes cable \& PC software. Version 314 offers all the features of 313 as well as $\mathrm{K}$ thermocouple input. The wet bulb globe temperature (WBGT) index is used in industry, sports and other areas to indicate the heat stress level for humans and animals. One of the values needed to calculate the WBGT Index is the black globe temperature. The black globe temperature is measured using a Black Globe Temperature Sensor which includes a black globe with a thermometer inserted in the center [15], Fig.1.

\section{B. The study sample}

The common compressed concrete paving units are used as measurement samples. The ultimate composition of compressed concrete is cement, aggregate and water. The constituent ratio is about water $(15-20 \%)$, cement (7$14 \%)$, and aggregate $(66-78 \%)$. The cement is white Portland cement and Portland cement. This study assumes the measurement sample material to be rich concrete: water:cement:aggregate $=20 \%: 14 \%: 66 \%$. The study sample size is $20 \mathrm{~cm} * 20 \mathrm{~cm} * 6 \mathrm{~cm}$. The ground tile type is the frequently used type in planning and design, described in Table 1:

TABLE I. THE STUDY SAMPLE

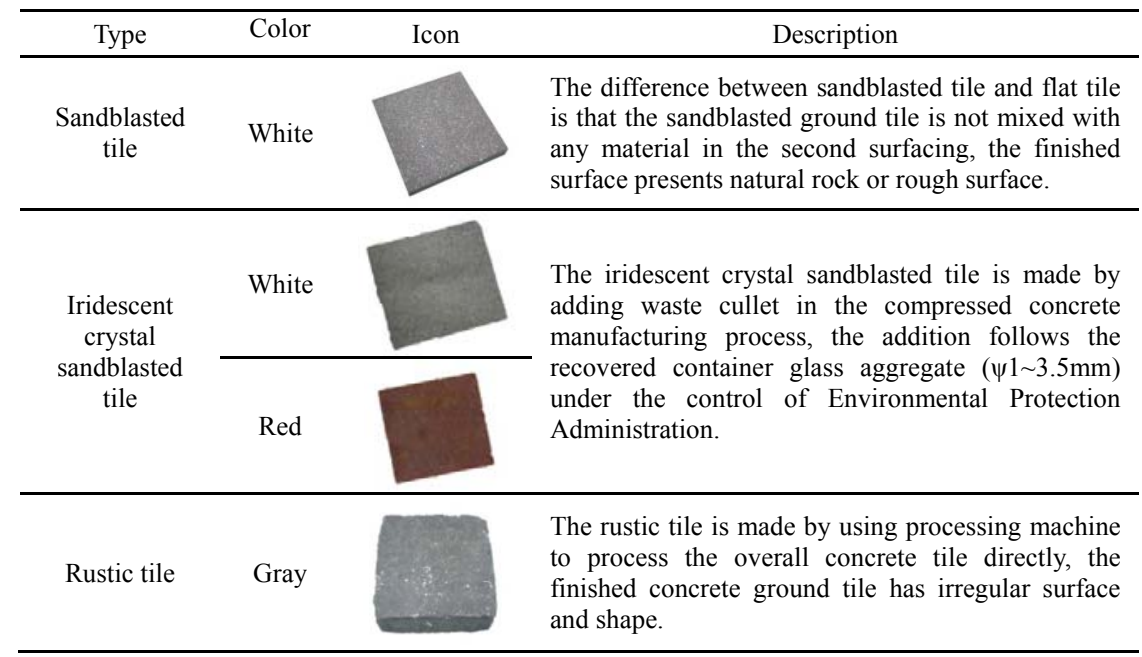




\section{Research Process}

\section{1) Measurement site and environment}

The measurement site is the rooftop of 7-story building research building of Kuang-Fu Campus, National Cheng Kung University, Tainan City. The measurement environment is free from plants, buildings and persons which may shade the sample, to avoid the measurement process being disturbed. The measurement is carried out on sunny days with sufficient sunshine amount, considering the influence of sun illumination angle on the sample in different seasons and hours. The measurement period is 10:00-14:00 in summer, and the average solar radiation quantity is above $800 \mathrm{~W} / \mathrm{m}^{2}$, so as to avoid too low reflectance of sample causing measurement error. As the solar angle is beveled in winter, the time is mainly $10: 30-13: 30$, and the average solar radiation quantity is also above $800 \mathrm{~W} / \mathrm{m}^{2}$.
Due to limited measurement manpower, one group of sample is measured per day. The different daily measurement climatic environments influence the sample measurement result, so the measurement and analysis are divided into experimental group and control group. The measurement result is discussed by the difference value between experimental group and control group, so as to provide specific comparison mode to discuss the measurement result.

\section{2) Measurement mold design}

According to literature review, the measurement of the reflectance of small-area material is likely to be influenced by ambient environment. A measurement aiding tool screening external environment is made referring to the experimental design of David J.Sailor [16], Fig. 2.

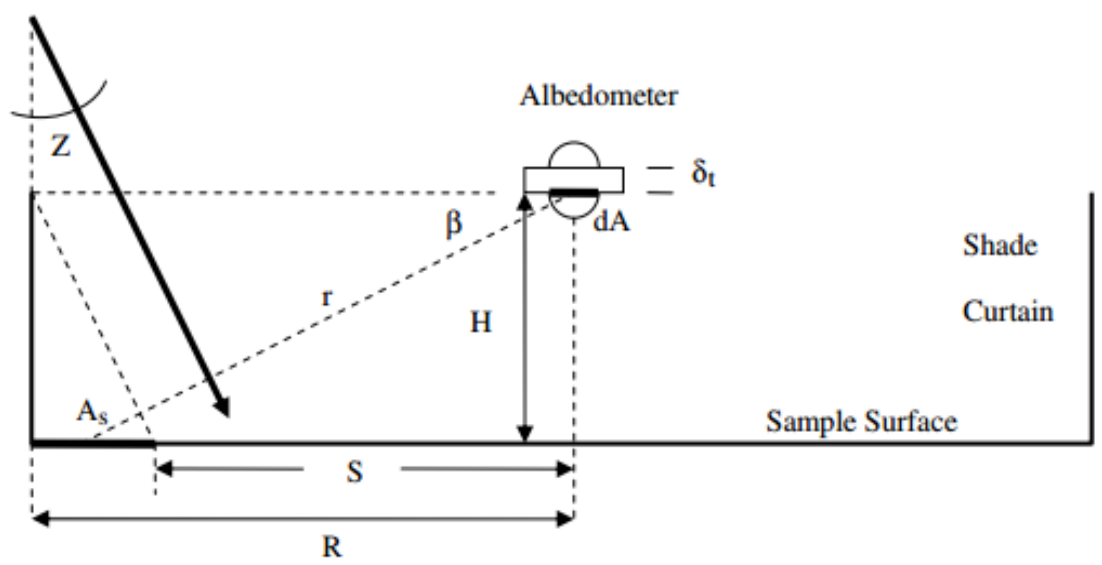

Figure 2. Albedo test stand showing dual pyranometer (albedometer), sample test

First, a wooden case in length, width and height of $40 \mathrm{~cm}$ is designed, Fig. 3. The test sample is put in the wooden case to avoid the environmental disturbance. The second step is to paint the interior of the case with black oil-based paint to avoid the secondary reflection inside the case. The third step is to unify the mounting height of

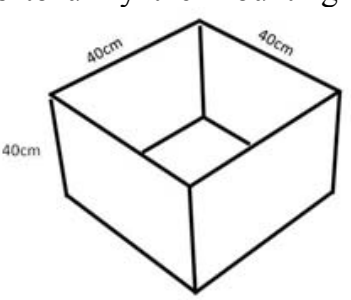

measuring instrument, the mounting devices are hard wooden bars to avoid long-term operation and solarization causing bending and errors. The mounting position is also marked to determine the same measurement position to reduce human errors.

Figure 3. Onsite wooden case and bearers

\section{RESULTS}

\section{A. Summer samples' reflectance.}

The samples in this study were classified into white sandblasted tile (control group: white flat tile), white iridescent crystal sandblasted tile (control group: white flat tile), red iridescent crystal sandblasted tile (control group: red flat tile) and gray rustic tile (control group: gray flat tile). Figure 4 shows the reflectance difference value of sandblasted tile and iridescent crystal sandblasted tile. The gray rustic tile and red iridescent crystal 
sandblasted tile have the minimum difference value. The reflectance of the two groups of samples is higher than control group. The white sandblasted tile has the maximum difference value.

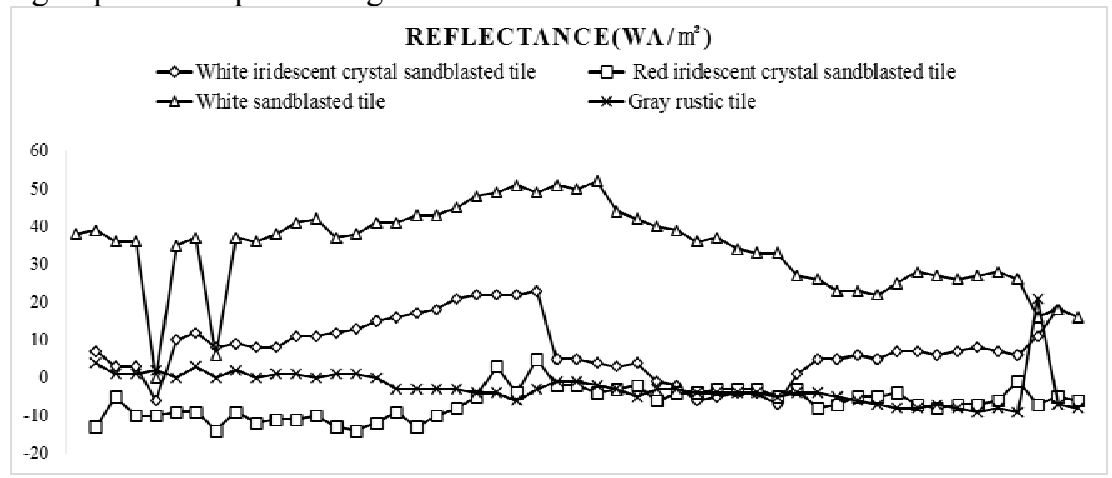

Figure 4. Summer samples' reflectance difference value change chart.

The findings show that the reflectance of red iridescent crystal sandblasted tile is 45 to $59 \mathrm{~W} / \mathrm{m}^{2}$, that of white iridescent crystal sandblasted tile is 66 to $71 \mathrm{~W} / \mathrm{m}^{2}$, the reflectance of white iridescent crystal sandblasted tile is higher than that of red iridescent crystal sandblasted tile by $10 \mathrm{~W} / \mathrm{m}^{2}$. The reflectance of white flat tile $(70-83$
$\mathrm{W} / \mathrm{m}^{2}$ ) is about $20 \mathrm{~W} / \mathrm{m}^{2}$ higher than the reflectance of red flat tile $\left(42-52 \mathrm{~W} / \mathrm{m}^{2}\right)$. The reflectance measurement result of the two groups of samples shows that reflectance gap between white ground tile and red ground tile decreases. The following table 2 shows the summer sample reflectance difference data.

TABLE II. SUMMER SAMPLES' REFLECTANCE DIFFERENCE VALUE DATA. (w/m²)

\begin{tabular}{ccccc}
\hline Sample material & $\begin{array}{c}\text { Selected } \\
\text { time }\end{array}$ & $\begin{array}{c}\text { Solar radiation } \\
\text { quantity }\end{array}$ & Reflectance & $\begin{array}{c}\text { Reflectance } \\
\text { difference value }\end{array}$ \\
\hline $\begin{array}{c}\text { White iridescent } \\
\text { crystal } \\
\text { sandblasted tile }\end{array}$ & $13: 00$ & 1520 & $66-76$ & $+5-+6$ \\
\hline $\begin{array}{c}\text { Red iridescent } \\
\text { crystal } \\
\text { sandblasted tile }\end{array}$ & $13: 00$ & 1526 & $45-59$ & $-3--7$ \\
\hline $\begin{array}{c}\text { White } \\
\text { sandblasted tile }\end{array}$ & $13: 00$ & 1508 & $45-58$ & $+16-+27$ \\
\hline Gray rustic tile & $13: 00$ & 1454 & $33-41$ & $-4--7$ \\
\hline
\end{tabular}

\section{B. Winter samples' reflectance.}

Figure 5 shows the reflectance difference values of sandblasted tile and iridescent crystal sandblasted tile. The gray rustic tile and red iridescent crystal sandblasted tile have the minimum difference value, and the white sandblasted tile has the maximum difference value.

\section{REFLECTANCE(WA/III)}

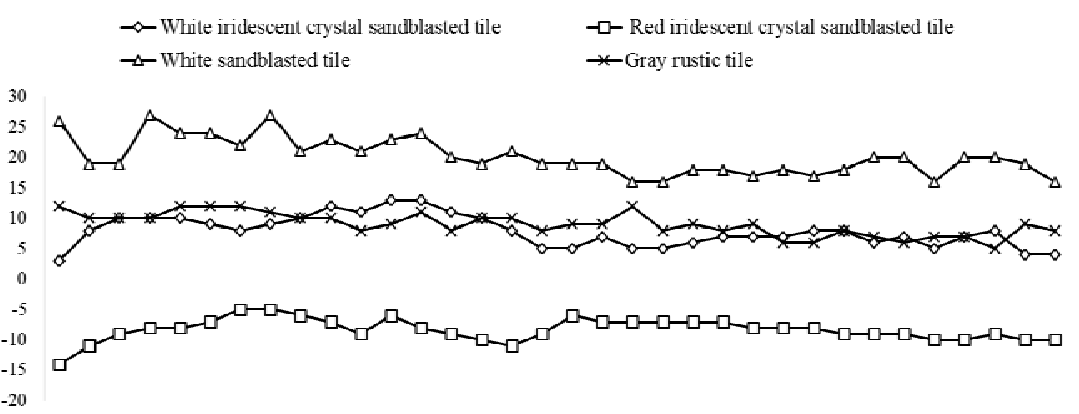

Figure 5. Winter samples' reflectance difference value change chart. 
The findings show that the reflectance of red iridescent crystal sandblasted tile is 47 to $49 \mathrm{~W} / \mathrm{m}^{2}$, that of white iridescent crystal sandblasted tile is 73 to $77 \mathrm{~W} / \mathrm{m}^{2}$. The reflectance of white iridescent crystal sandblasted tile is about $20 \mathrm{~W} / \mathrm{m}^{2}$ higher than the reflectance of red iridescent crystal sandblasted tile. It is increased in comparison to the summer sample measurement value.
The reflectance of white flat tile $\left(81-84 \mathrm{~W} / \mathrm{m}^{2}\right)$ is about $30 \mathrm{~W} / \mathrm{m}^{2}$ higher than the reflectance of red flat tile $\left(55-58 \mathrm{~W} / \mathrm{m}^{2}\right)$. The reflectance measurement result of the two groups of samples is the same as summer measurement, that the reflectance gap between white ground tile and red ground tile is reduced. The following table 3 shows the winter sample reflectance difference data.

TABLE III. WINTER SAMPLES' REFLECTANCE DIFFERENCE VALUE DATA. (W/m²)

\begin{tabular}{ccccc}
\hline Sample material & $\begin{array}{c}\text { Selected } \\
\text { time }\end{array}$ & $\begin{array}{c}\text { Solar radiation } \\
\text { quantity }\end{array}$ & Reflectance & $\begin{array}{c}\text { Reflectance } \\
\text { difference value }\end{array}$ \\
\hline $\begin{array}{c}\text { White iridescent crystal } \\
\text { sandblasted tile }\end{array}$ & $13: 00$ & 1226 & $77-73$ & $+7-+8$ \\
\hline $\begin{array}{c}\text { Red iridescent crystal } \\
\text { sandblasted tile }\end{array}$ & $13: 00$ & 919 & $47-49$ & $-5--6$ \\
\hline White sandblasted tile & $13: 00$ & 1572 & $56-58$ & $+20-+16$ \\
\hline Gray rustic tile & $13: 00$ & 1055 & $38-40$ & $-15--16$ \\
\hline
\end{tabular}

\section{CONCLUSIONS}

According to the experimental results, after the surface treatment of flat tile, the reflectance is reduced by $5-8$ $\mathrm{W} / \mathrm{m}^{2}$ compared with the iridescent crystal sandblasted tile, and that of sandblasted tile is reduced by $16-27 \mathrm{~W} / \mathrm{m}^{2}$. The difference between the sample and white flat tile (control group) is small, the solar radiation quantity is small in winter, so the reflectance difference value is small. On the other hand, the sample reflectance of the control group white flat tile without any constituent is 71$82 \mathrm{~W} / \mathrm{m}^{2}$. However, after it is mixed with iridescent crystal (waste glass) to become iridescent crystal sandblasted tile, the sample reflectance is reduced by $5-6$ $\mathrm{W} / \mathrm{m}^{2}$. Therefore, the findings show that the compressed concrete paving units without treatment have the best reflectance, it is unnecessary to add other constituents in them. This study suggests that in order to reduce the urban heat island effect, the white flat tiles without special treatment can be selected as the material for urban outdoor pavement design. Thus, the carbon emission from special treatment can be reduced, and a good reflectance effectiveness can be obtained.

\section{REFERENCES}

[1] Chandler, T. J., Wind as a factor of urban temperatures: A survey in north-east London, Weather, 15, pp.204-213, 2014.

[2] Oke, T. R., Boundary Layer Climates. Psychology Press, 1987.

[3] Thomas, R. K. \& Philip, D. J., Urban biases in area-averaged surface air temperature trends. American meteorological society, 70, pp.265-270, 1989.

[4] Racine, T. A. P. \& Fabianal, L. F., Measurement of albedo and analysis of its influence the surface. Energy and Buildings, 37, pp.295-300, 2005.

[5] Li, H., Harvry, J. \& Jones, D. Field measurement of albedo for different land cover materials and effectson thermal performance. Building and Environment, 59, pp.1-11, 2013.

[6] Haider, T. Urban climates and heat islands: albedo, evapotranspiration, and anthropogenic heat. Energy and Buildings, 25, pp.99-103, 1997.

[7] Yu, B. F., Chen, Z. \& Shang, P. J. Study on the influence of albedo on building heat environment in a year-round. Energy and Buildings, 40, PP.945-951, 2008.

[8] David, J. S., Kyle, R. \& Del, S. Field measurement of albedo for limited extent test surfaces. Solar Energy, 80, pp.589-599, 2006.

[9] Navigant Consulting Inc. Building technologies program, assessment of international urban heat island research - literature review of international studies on urban heat island countermeasures. Draft report. USDOE. Washington, DC.: Office of Energy Efficiency and Renewable Energy, 2011.

[10] Hashem, A. \& Damon, M. Global cooling updates: reflective roofs and pavements. Energy and Build, 55, pp.2-6, 2012.

[11] Jo, J. H., Carlson, J. D., Golden, J. S. \& Bryan, H. An integrated empirical and modeling methodology for analyzing solar reflective roof technologies on commercial buildings. Building and Environment, 45, pp.453-460, 2010.

[12] Takashi, A. \& Vu, T. A. Characteristics of permeable pavement during hot summer weather and impact on the thermal environment. Building and Environment, 35, pp.363-375, 2000.

[13] Synnefa, A., Karlassi, T., Gaitani, N., Santamouris, M., Assimakopoulos, D. N. \& Papakatsikas. Experimental testing of cool colored thin layer asphalt and estimation of its potential to improve the urban microclimate. Building and Environment, 46, pp.38-44, 2011.

[14] Santamouris, M., Gaitani, N., Spanou, A., Saliari, M., Giannopoulou, K. \& Vasilakopoulou, K. Using cool paving materials to improve microclimate of urban areas - design realization and results of the flisvos project. Building and Environment, 53, pp.128-136, 2012.

[15] David, J. S., Kyle, R. \& Del, S. Field measurement of albedo for limited extent test surfaces. Solar Energy, 80, pp.589-599, 2006.

[16] Vincent, E. D., Steven, F. P. \& Steven, A. A. Estimation of Black Globe Temperature for Calculation of the Wet Bulb Globe Temperature Index. Proceedings of the World Congress on Engineering and Computer Science, 2011. 